\title{
Effect of preoperative non-dialysis-dependent renal dysfunction on isolated aortic and mitral valve surgery: A propensity score analysis
}

\author{
Luis Garrido-Olivares, MD, MSc, ${ }^{\mathrm{a}}$ Tirone E. David, MD, ${ }^{\mathrm{a}}$ Manjula Maganti, MSc, ${ }^{\mathrm{a}}$ \\ Duminda Wijeysundera, MD, FRCPC, ${ }^{\mathrm{b}}$ and Vivek Rao, MD, PhD, FRCSC ${ }^{\mathrm{a}}$
}

\begin{abstract}
Objective: Our objective was to examine whether preoperative non-dialysis-dependent renal dysfunction is associated with operative mortality or morbidity in isolated valve surgery.

Methods: We reviewed consecutive patients undergoing isolated aortic $(n=2132)$ or mitral valve $(n=1664)$ surgery, between 1996 and 2009. Preoperative renal dysfunction was defined as preoperative estimated glomerular filtration rate $<60 \mathrm{~mL} / \mathrm{min}$ without dialysis. Propensity score 1:1 matched samples were created, one for aortic $(\mathrm{n}=626)$ and one for mitral $(\mathrm{n}=526)$ valve surgery.
\end{abstract}

\begin{abstract}
Results: The mean age was $70 \pm 9$ and $65 \pm 10$ years for the aortic and mitral groups, respectively. In the aortic cohort, patients with preoperative renal dysfunction had greater need for inotropes $(39 \%$ vs $29 \% ; P=.009)$, length of intensive care unit stay ( 27 vs 25 hours; $P=.006$ ), and duration of mechanical ventilation ( 8.2 vs 6.6 hours; $P<.001$ ). Operative mortality was $3.2 \%$ in the group with preoperative renal dysfunction and $2.2 \%$ in the group without preoperative renal dysfunction $(P=.5)$. In the mitral cohort, patients with preoperative renal dysfunction had greater need for inotropes $(47 \%$ vs $36 \% ; P=.013)$, length of intensive care unit stay (40 vs 26 hours; $P=.01$ ), and duration of mechanical ventilation (7.2 vs 6.5 hours; $P=.004$ ). Operative mortality was $0 \%$ and $2.7 \%$ in the groups without and with preoperative renal dysfunction, respectively $(P=.015)$.

Conclusions: Preoperative renal dysfunction is associated with higher morbidity in both cohorts, and patients undergoing mitral valve surgery also experienced higher mortality. The impact of non-dialysis-dependent preoperative renal dysfunction appears to be more pronounced in patients undergoing mitral valve surgery, potentially owing to their relative intolerance to volume overload. (J Thorac Cardiovasc Surg 2011;142:155-61)
\end{abstract}

Chronic kidney disease is a significant public health problem whose prevalence is progressively increasing in the world, particularly in developed countries. ${ }^{1,2}$ Chronic kidney disease is a widely known risk factor for the development and progression of cardiovascular diseases and currently affects approximately 2 million Canadians, which accounts for $6 \%$ of the total population in Canada. ${ }^{3-5}$ As a consequence, preoperative renal dysfunction (PRD) is prevalent in patients undergoing cardiovascular surgery. In a recent multicenter Canadian cohort study, approximately $30 \%$ of the patients undergoing cardiovascular surgery had an estimated preoperative glomerular filtration rate (GFR) less than $60 \mathrm{~mL} / \mathrm{min}^{6}$

The implications of kidney failure with chronic renal replacement therapy (chronic kidney disease stage 5) on cardiovascular surgical outcomes are widely known. ${ }^{7-10}$ Also,

From the Division of Cardiovascular Surgery, ${ }^{\mathrm{a}}$ Peter Munk Cardiac Centre, Toronto General Hospital and University of Toronto; and the Department of Anesthesia, ${ }^{b}$ Toronto General Hospital and University of Toronto, Toronto, Ontario, Canada.

Disclosures: Authors have nothing to disclose with regard to commercial support.

Received for publication July 7, 2010; revisions received Oct 26, 2010; accepted for publication Dec 6, 2010; available ahead of print Jan 31, 2011.

Address for reprints: Vivek Rao, MD, PhD, Alfredo and Teresa DeGasperis Chair in

Heart Failure Surgery, Toronto General Hospital, 4N-464, 200 Elizabeth St, Tor-

onto, Ontario M5G 2C4, Canada (E-mail: vivek.rao@uhn.on.ca).

$0022-5223 / \$ 36.00$

Copyright (C) 2011 by The American Association for Thoracic Surgery

doi:10.1016/j.jtcvs.2010.12.005 the influence of the preoperative renal function on the development of postoperative acute renal failure and on operative mortality (OM) after cardiac surgery has been documented. ${ }^{10}$ In addition, multiple studies have shown increased mortality and morbidity in patients undergoing coronary artery bypass graft (CABG) surgery with nondialysis-dependent chronic renal failure. ${ }^{11-14}$ PRD has also been found to be a significant predictor of late mortality in CABG surgery. ${ }^{15}$ However, in isolated valve surgery, the association between PRD and mortality and morbidity has not been as well defined. We also hypothesized that the impact of PRD may be different in patients undergoing aortic valve surgery (AVS), primarily for pressure overload physiology, versus mitral valve surgery (MVS) for predominantly volume overload pathology.

\section{METHODS}

\section{Ethical Requirements and Study Setting}

The University of Toronto Research Ethics Board approved this study, and given the observational study design, an individual patient consent was waived. The study setting is the Toronto General Hospital in Toronto, Ontario, Canada.

\section{Study Design and Participants}

From a cohort of patients who underwent cardiac surgery at the Toronto General Hospital between 1996 and 2009, we reviewed consecutive patients undergoing isolated aortic (AVS: $\mathrm{n}=2132$ ) or mitral valve (MVS: $\mathrm{n}=1664$ ) surgery. All data were prospective collected by a full-time 


$$
\begin{aligned}
& \text { Abbreviations and Acronyms } \\
& \text { AVS = aortic valve surgery } \\
& \text { BSA }=\text { body surface area } \\
& \text { CABG }=\text { coronary artery bypass graft } \\
& \text { GFR }=\text { glomerular filtration rate } \\
& \text { IQR }=\text { interquartile range } \\
& \text { LCOS }=\text { low cardiac output syndrome } \\
& \text { MVS }=\text { mitral valve surgery } \\
& \text { OM }=\text { operative mortality } \\
& \text { PRD }=\text { preoperative renal dysfunction }
\end{aligned}
$$

professional research team. The quality of the data was assessed by random interrogation and the final edition stored in a computerized database after external validation.

\section{PRD Classification}

PRD was defined as preoperative estimated GFR less than $60 \mathrm{~mL} / \mathrm{min}$ without the need for dialysis using the Cockcroft-Gault formula. ${ }^{9}$ The selection of this formula was based on its worldwide use and extensive temporal and external validation since its publication in 1976. In addition, the discrimination ability for $\mathrm{OM}$ after cardiovascular surgery using the Cockcroft-Gault formula has been reported as similar in comparison with a new method, the Modification of Diet in Renal Disease equation. ${ }^{9,16}$

\section{Covariables}

The following preoperative variables were included: sex, age, body surface area (BSA), family history of cardiac disease, and associated comorbidities including, diabetes mellitus, hypertension, hyperlipidemia, chronic obstructive pulmonary disease, previous stroke or transitory ischemic attack, peripheral vascular disease, carotid disease, previous cardiac operations, previous CABG surgery, active endocarditis, previous or active endocarditis, New York Heart Association functional class, angina, urgent or emergency surgery, congestive heart failure, left ventricular ejection fraction, smoking, preoperative myocardial infarction, and pre-existing atrial fibrillation. Clinical variables were defined using standard operational definitions. ${ }^{6,10,11,13}$

The following intraoperative variables were collected: cardiopulmonary bypass time, aortic crossclamp time, valvular replacement, valvular repair, annular enlargement in AVS, or annular reconstruction in MVS.

\section{Outcomes}

The primary outcome was $\mathrm{OM}$ and was defined as any death during the index hospital admission or during the first 30 postoperative days. The following secondary outcome variables were collected: reoperation for any cause, perioperative myocardial infarction, low cardiac output syndrome (LCOS), perioperative stroke, renal failure (defined as need for renal replacement therapy), sternal wound infection, sepsis, pulmonary complication, atrial fibrillation, use of intra-aortic balloon pump, use of inotropes, length of mechanical ventilation, length of stay in the intensive care unit, and postoperative length of stay.

\section{Statistical Analysis}

Categorical variables are reported as number and percentages. Continuous variables are expressed as mean and standard deviation or median and interquartile range (IQR). All statistical analyses were performed with the SAS 9.1 software (SAS Institute, Inc, Cary, NC). Statistical analysis was performed using the $\chi^{2}$ test or Fisher exact test for categorical variables and $t$ tests or Kruskal-Wallis equality-of-populations rank test for continuous variables where appropriate. Propensity score 1:1 matched samples were created independently; one for AVS and one for MVS. The propensity score methodology was in accordance with Rosenbaum and associates $^{17,18}$ and the current state of the art literature. ${ }^{19-21}$ Technical aspects are presented in Appendices 1-3.

Considering the quality of the database and the minimal percentage of missing data (data not reported), no multiple imputation techniques were considered. Also, no adjustment for multiplicity was considered in the analyses. Finally, all the analyses were performed independently for the AVS and MVS matched sample groups.

\section{RESULTS}

\section{Characteristics of the Propensity Score-Matched Samples}

The match selected 626 and 526 patients in the AVS and MVS samples who were well matched with a mean age of $70 \pm 9$ and $65 \pm 10$ years, respectively. The clinical characteristics of the matched samples are presented in Tables 1 (AVS) and 2 (MVS). As expected with the propensity score matching technique, there were no significant differences between the PRD and non-PRD patients in either cohort of valve surgery. The only exception was the BSA, which was smaller in the PRD groups (AVS: $1.75 \pm 0.21$ vs 1.94 $\pm 0.20 \mathrm{~m}^{2}, P<.001$; MVS: $1.70 \pm 0.19$ vs $1.88 \pm 0.23$ $\left.\mathrm{m}^{2}, P<.001\right)$ of both cohorts. The type of valvular lesion and operative techniques were not statistically different between groups in either cohort (Appendix 4). The type of valvular lesion in both samples is presented in Appendix 4. Finally, the perioperative and outcome variables for AVS and MVS are presented in Tables 3 and 4, respectively.

\section{Primary Outcomes of the Propensity-Matched Samples}

In the AVS cohort, OM was similar $(2.2 \%$ vs $3.2 \%$; $P=.5)$ in the non-PRD and PRD groups. In contrast, in the MVS cohort OM was lower in the non-PRD group $(0 \%$ vs $2.7 \% ; P=.015)$ (Figure 1$)$. The timing and causes of OM in the MVS cohort are presented in Appendix 5.

\section{Secondary Outcomes in the AVS Group}

In the AVS group, patients with PRD had greater need for inotropes ( $39 \%$ vs $29 \% ; P=.009)$, duration of mechanical ventilation ( 8 hours [IQR $=9$ hours] vs 7 hours [IQR $=5$ hours]; $P<.001)$ and length of intensive care unit stay (27 hours [IQR $=46$ hours] vs 25 hours [IQR $=27$ hours]; $P=.006)$. There were no significant differences between groups in need for reoperation, perioperative myocardial infarction, LCOS, perioperative stroke, renal failure, sternal wound infection, sepsis, pulmonary complication, atrial fibrillation, use of intra-aortic balloon pump, and postoperative length of stay (Table 3 ).

\section{Secondary Outcomes in the MVS Group}

In the MVS group, patients with PRD had greater need for inotropes $(47 \%$ vs $36 \% ; P=.013)$, duration of 
TABLE 1. Clinical characteristics of the matched aortic valve surgery groups (n = 313/group)

\begin{tabular}{lcrcrc}
\hline \multicolumn{1}{c}{ Variable } & \multicolumn{2}{c}{ Non-PRD } & PRD & P value \\
\hline Male sex & $56.9 \%$ & 178 & $53.0 \%$ & 166 & $.335 \ddagger$ \\
Age (y): mean (SD) & $70.5(8.26)$ & & $70.4(9.39)$ & & $.910 *$ \\
BSA $\left(\mathrm{m}^{2}\right)$ : mean (SD) & $1.94(0.20)$ & & $1.75(0.21)$ & & $<.001 * \dagger$ \\
Family history & $38.5 \%$ & 120 & $33.0 \%$ & 103 & $.156 \ddagger$ \\
NYHA III or IV & $71.6 \%$ & 224 & $70.0 \%$ & 219 & $.593 \ddagger$ \\
CHF & $51.1 \%$ & 160 & $49.8 \%$ & 156 & $.749 \ddagger$ \\
Angina & $1.3 \%$ & 4 & $1.3 \%$ & 4 & $1.0 \S$ \\
Urgent/emergency & $4.5 \%$ & 14 & $6.1 \%$ & 19 & $.789 \ddagger$ \\
Redo CABG & $6.1 \%$ & 19 & $3.5 \%$ & 11 & $.134 \ddagger$ \\
Any redo & $16.0 \%$ & 50 & $13.7 \%$ & 43 & $.432 \ddagger$ \\
COPD & $5.1 \%$ & 16 & $7.0 \%$ & 22 & $.315 \ddagger$ \\
LVEF < 40\% & $11.8 \%$ & 37 & $16.9 \%$ & 53 & $.168 \ddagger$ \\
Diabetes & $13.4 \%$ & 42 & $13.4 \%$ & 42 & $1.0 \ddagger$ \\
Hypertension & $49.8 \%$ & 156 & $49.8 \%$ & 156 & $1.0 \ddagger$ \\
Hyperlipidemia & $42.2 \%$ & 132 & $39.6 \%$ & 124 & $.516 \ddagger$ \\
PVD & $8.9 \%$ & 28 & $8.3 \%$ & 26 & $.776 \ddagger$ \\
Active endocarditis & $1.9 \%$ & 6 & $3.2 \%$ & 10 & $.391 \ddagger$ \\
Any endocarditis & $5.8 \%$ & 18 & $5.1 \%$ & 16 & $.724 \ddagger$ \\
Preop. MI & $1.6 \%$ & 5 & $1.3 \%$ & 4 & $.737 \S$ \\
Stroke/TIA & $9.6 \%$ & 30 & $8.9 \%$ & 28 & $.783 \ddagger$ \\
AF & $9.3 \%$ & 29 & $8.9 \%$ & 28 & $.890 \ddagger$ \\
\hline
\end{tabular}

$P R D$, Preoperative renal dysfunction; $S D$, standard deviation; $B S A$, body surface area; $N Y H A$, New York Heart Association; $C H F$, congestive heart failure; Redo CABG, previous coronary artery bypass graft surgery; Any redo, previous cardiac surgery; $C O P D$, chronic obstructive pulmonary disease; $L V E F$, left ventricular ejection fraction; $P V D$, peripheral vascular disease; Preop. $M I$, preoperative myocardial infarction; TIA, transitory ischemic attack; $A F$, atrial fibrillation. *Two-sample $t$ test. $\dagger P<.05 . \ddagger \chi^{2}$ test. $\S$ Fisher exact test.

mechanical ventilation ( 7 hours [IQR $=7$ hours] vs 6 hours $[\mathrm{IQR}=5$ hours $] ; P=.004)$, and length of intensive care unit stay ( 40 hours [IQR $=47$ hours] vs 26 hours [IQR $=27$ hours]; $P=.011)$. As in the AVS cohort, there were no significant differences between groups in need for reoperation, perioperative myocardial infarction, LCOS, perioperative stroke, renal failure, sternal wound infection, sepsis, pulmonary complication, atrial fibrillation, use of intra-aortic balloon pump, or postoperative length of stay (Table 4).

\section{DISCUSSION}

In patients undergoing isolated valve surgery, we identified PRD to be associated with perioperative mortality after MVS but not AVS. However, the presence of PRD led to clinically significant morbidity in both cohorts.

Anderson and coworkers ${ }^{22}$ in 2000 reported mild renal insufficiency as an independent risk factor for adverse outcomes after cardiac valve surgery. Their sample, which included 834 patients undergoing valvular surgery with or without concomitant CABG from 14 Veterans' Affairs Medical Centers between 1992 and 1996, was stratified as normal renal function (serum creatinine $<1.5 \mathrm{mg} / \mathrm{dL}$, $\mathrm{n}=637$ ), mild-to-moderate renal failure (serum creatinine between 1.5 and $3.0 \mathrm{mg} / \mathrm{dL}, \mathrm{n}=183$ ), and advanced renal failure (serum creatinine $>3.0 \mathrm{mg} / \mathrm{dL}, \mathrm{n}=14$ ). In a multi-
TABLE 2. Clinical characteristics of the matched mitral valve surgery groups ( $n=263$ group)

\begin{tabular}{lcccrc}
\hline \multicolumn{1}{c}{ Variable } & \multicolumn{2}{c}{ Non-PRD } & PRD & & $\boldsymbol{P}$ value \\
\hline Male sex & $39.9 \%$ & 105 & $39.2 \%$ & 103 & $.858 \ddagger$ \\
Age (y): mean (SD) & $64.6(9.83)$ & & $64.4(11.05)$ & & $.878 *$ \\
BSA (m $\left.{ }^{2}\right)$ : mean (SD) & $1.88(0.23)$ & & $1.70(0.19)$ & & $<.001 * \dagger$ \\
Family history & $40.1 \%$ & 105 & $34.0 \%$ & 89 & $.148 \ddagger$ \\
NYHA III or IV & $70.0 \%$ & 184 & $71.5 \%$ & 188 & $.702 \ddagger$ \\
CHF & $65.0 \%$ & 171 & $62.4 \%$ & 164 & $.526 \ddagger$ \\
Angina & $6.1 \%$ & 16 & $7.6 \%$ & 20 & $.499 \ddagger$ \\
Urgent/emergency & $2.3 \%$ & 6 & $4.2 \%$ & 11 & $.218 \ddagger$ \\
Redo CABG & $4.2 \%$ & 11 & $3.4 \%$ & 9 & $.648 \ddagger$ \\
Any redo & $16.7 \%$ & 44 & $20.2 \%$ & 53 & $.312 \ddagger$ \\
COPD & $4.2 \%$ & 11 & $3.4 \%$ & 9 & $.649 \ddagger$ \\
LVEF < 40\% & $6.5 \%$ & 17 & $9.1 \%$ & 24 & $.255 \ddagger$ \\
Diabetes & $11.4 \%$ & 30 & $8.0 \%$ & 21 & $.185 \ddagger$ \\
Hypertension & $38.0 \%$ & 100 & $32.7 \%$ & 86 & $.202 \ddagger$ \\
Hyperlipidemia & $29.7 \%$ & 78 & $26.2 \%$ & 69 & $.382 \ddagger$ \\
PVD & $2.3 \%$ & 6 & $2.3 \%$ & 6 & $1.0 \ddagger$ \\
Active endocarditis & $2.7 \%$ & 7 & $4.9 \%$ & 13 & $.171 \ddagger$ \\
Any endocarditis & $8.0 \%$ & 21 & $9.9 \%$ & 26 & $.445 \ddagger$ \\
Preop MI & $0.8 \%$ & 2 & $0.8 \%$ & 2 & $1.0 \S$ \\
Stroke/TIA & $8.8 \%$ & 23 & $12.2 \%$ & 32 & $.200 \ddagger$ \\
AF & $35.0 \%$ & 92 & $33.5 \%$ & 88 & $.713 \ddagger$ \\
\hline PRD, Preop & & $9.5 \%$ &
\end{tabular}

$P R D$, Preoperative renal dysfunction; $S D$, standard deviation; $B S A$, body surface area; $N Y H A$, New York Heart Association; $C H F$, congestive heart failure; Redo $C A B G$, previous coronary artery bypass graft surgery; Any redo, previous cardiac surgery; $C O P D$, chronic obstructive pulmonary disease; $L V E F$, left ventricular ejection fraction; $P V D$, peripheral vascular disease; Preop $M I$, preoperative myocardial infarction; $T I A$, transitory ischemic attack; $A F$, Atrial fibrillation. *Two-sample $t$ test. $\dagger P<.05$. $\ddagger \chi^{2}$ test. §Fisher exact test.

variable logistic regression model, mild-to-moderate renal failure was associated with $\mathrm{OM}(P=.001)$ and postoperative morbidity. However, only 73 patients in their study displayed mild-to-moderate renal failure. In addition to a highly selected population of veterans, they did not independently examine the effects of renal function on AVS and MVS.

Abramov and associates ${ }^{23}$ in 2003 reported preoperative renal dysfunction as an independent predictor of mortality and morbidity in a sample of 2214 patients, predominatly isolated CABG $(82 \%)$ with only $5 \%$ and $4 \%$ undergoing AVS and MVS, respectively. Preoperative creatinine clearance less than $0.84 \mathrm{~mL} \cdot \mathrm{s}^{-1} \cdot \mathrm{m}^{-2}$ was correlated with an exponential increase in a composite outcome of perioperative mortality, myocardial infarction, LCOS, and cerebrovascular accident. Again, their study had a very small sample of valve patients and did not report the results of AVS and MVS separately. Our study focuses selectively on isolated valve surgery and, with a relatively larger sample size, we were able to demonstrate a clear difference between aortic and mitral populations. Owing to the fact that we intentionally excluded patients requiring preoperative renal replacement therapy, we did not stratify patients according to the severity of renal dysfunction as per Anderson, ${ }^{22}$ Filsoufi, ${ }^{24}$ and their associates. Similar to our results 
TABLE 3. Perioperative data in the matched aortic valve surgery groups

\begin{tabular}{|c|c|c|c|}
\hline Variable & $\begin{array}{l}\text { Non-PRD } \\
(n=313)\end{array}$ & $\begin{array}{c}\text { PRD } \\
(\mathbf{n}=\mathbf{3 1 3})\end{array}$ & $\begin{array}{c}P \\
\text { value }\end{array}$ \\
\hline CPB time (min): mean (SD) & $101(40.1)$ & $96(35.1)$ & $.100^{*}$ \\
\hline Crossclamp time (min): mean (SD) & $77(32.5)$ & $73(27.5)$ & $.092 *$ \\
\hline Aortic valve replacement: n (\%) & $290(92.7 \%)$ & $297(94.9 \%)$ & $.247 \ddagger$ \\
\hline Aortic annulus enlargement: $\mathrm{n}(\%)$ & $62(19.8 \%)$ & $50(16.0 \%)$ & $.204 \ddagger$ \\
\hline Reoperation: $\mathrm{n}(\%)$ & $28(8.9 \%)$ & $35(11.2 \%)$ & $.352 \ddagger$ \\
\hline Postoperative bleeding: $\mathrm{n}(\%)$ & $22(7.0 \%)$ & $25(8.0 \%)$ & $.649 \ddagger$ \\
\hline Postoperative tamponade: $\mathrm{n}(\%)$ & $3(1.0 \%)$ & $5(1.6 \%)$ & $.725 \|$ \\
\hline Mortality: n (\%) & $7(2.2 \%)$ & $10(3.2 \%)$ & $.461 \ddagger$ \\
\hline Ventilation time (h): median (IQR) & $6.6(5.0)$ & $8.2(9.4)$ & $<.001 \dagger^{\dagger} \S$ \\
\hline LICU (h): median (IQR) & $24.8(26.9)$ & $27.4(46.1)$ & $.006 \dagger ` \S$ \\
\hline $\begin{array}{l}\text { Postoperative stay (d): median } \\
\text { (IQR) }\end{array}$ & $7(4)$ & $8(5)$ & $.163 \S$ \\
\hline LCOS: n $(\%)$ & $7(2.2)$ & $10(3.2)$ & .457 \\
\hline Myocardial Infarction: n (\%) & $3(1.0 \%)$ & $3(1.0 \%)$ & $1.0 \|$ \\
\hline Sternal wound infection: $\mathrm{n}(\%)$ & $6(1.9 \%)$ & $3(1.0 \%)$ & $.505 \|$ \\
\hline Sepsis: n (\%) & $3(1.0 \%)$ & $5(1.6 \%)$ & $.725 \|$ \\
\hline Stroke $(\%)$ & $8(2.6 \%)$ & $7(2.2 \%)$ & $.794 \ddagger$ \\
\hline Pulmonary complication: $\mathrm{n}(\%)$ & $29(9.3 \%)$ & $39(12.5 \%)$ & $.199 \ddagger$ \\
\hline Renal failure: n (\%) & $3(1.0 \%)$ & $7(2.2 \%)$ & $.340 \|$ \\
\hline Atrial fibrillation: $\mathrm{n}(\%)$ & $112(35.8 \%)$ & $95(30.4 \%)$ & $.149 \ddagger$ \\
\hline IABP: n (\%) & $4(1.3 \%)$ & $7(2.2 \%)$ & $.545 \|$ \\
\hline Use of inotropes: $\mathrm{n}(\%)$ & $91(29.1 \%)$ & $122(39.0 \%)$ & $.009 \dagger \dagger$ \\
\hline
\end{tabular}

in AVS, Ibáñez and coworkers ${ }^{25}$ reported in a sample of 681 valvular patients with or without concomitant CABG, no difference in OM between patients with $(\mathrm{n}=207)$ or without $(\mathrm{n}=474)$ PRD $(3.4 \%$ vs $2.3 \% ; P=.43)$. The main finding of their study was that PRD patients had a higher incidence of reoperation $(6.8 \%$ vs $2.3 \% ; P<.001)$, red blood cell transfusions, longer ventilation time, and hospital stay. Unfortunately, their study had a severe demographic imbalance between groups and they did not use a propensity score analysis to adjust risk. We did not investigate total transfusion requirements, but we also found differences in ventilation time and postoperative length of stay.

Howell and associates ${ }^{26}$ reported that mild renal dysfunction, defined as an estimated GFR less than $60 / \mathrm{mL}$ per $1.73 \mathrm{~m}^{2}$, was a predictor of early and late mortality. These authors stratified renal risk according to estimated GFR and found renal dysfunction in $74 \%$ of their 7621 patient cohort. Their sample included 1756 (23\% of the entire surgical cohort) patients with valve surgery. The in-hospital mortality was $3.2 \%$ and directly correlated to the degree of renal dysfunction. Multivariate analysis demonstrated a stronger correlation in patients undergoing isolated CABG (odds ratio $=12.2$ ), but a mortality effect persisted in patients undergoing valvular surgery. Unfortunately, this
TABLE 4. Perioperative data in the matched mitral valve surgery groups

\begin{tabular}{|c|c|c|c|}
\hline Variable & $\begin{array}{c}\text { Non-PRD } \\
\mathbf{n}=\mathbf{2 6 3} \\
\end{array}$ & $\begin{array}{c}\text { PRD } \\
\mathrm{n}=\mathbf{2 6 3}\end{array}$ & $\begin{array}{c}P \\
\text { value }\end{array}$ \\
\hline$(\min )$ : mean $(\mathrm{SD})$ & $89.3(38.4)$ & $92(37.1)$ & $.497 *$ \\
\hline $\begin{array}{l}\text { Crossclamp time }(\mathrm{min}) \text { : } \\
\text { mean }(\mathrm{SD})\end{array}$ & $68(29.5)$ & $70(34.9)$ & $.379 *$ \\
\hline Mitral valve replacement: $\mathrm{n}(\%)$ & $127(48.3 \%)$ & $148(55.3 \%)$ & $.067 \ddagger$ \\
\hline $\begin{array}{l}\text { Mitral annulus reconstruction: } \\
\mathrm{n}(\%)\end{array}$ & $9(3.4 \%)$ & $15(5.7 \%)$ & $.206 \ddagger$ \\
\hline Reoperation: $\mathrm{n}(\%)$ & $14(5.3 \%)$ & $17(6.5 \%)$ & $.579 \ddagger$ \\
\hline Postoperative bleeding: $\mathrm{n}(\%)$ & $8(3.0 \%)$ & $14(5.3 \%)$ & $.191 \ddagger$ \\
\hline Postoperative tamponade: $\mathrm{n}(\%)$ & $2(0.8 \%)$ & $3(1.1 \%)$ & $1.0 \|$ \\
\hline Mortality: n (\%) & $0(0 \%)$ & $7(2.7 \%)$ & $.015 \dagger^{\dagger}$ \\
\hline Ventilation time (h): median (IQR) & $6.5(5.4)$ & $7.2(6.6)$ & $.004 \dagger^{\prime} \S$ \\
\hline LICU (h): median (IQR) & $26.2(26.5)$ & $39.8(47.3)$ & $.011 \dagger^{\prime} \S$ \\
\hline $\begin{array}{l}\text { Postoperative stay (d): median } \\
\text { (IQR) }\end{array}$ & $7(5)$ & $8(4)$ & $.310 \S$ \\
\hline LCOS: n (\%) & $3(1.1)$ & $9(3.4)$ & $.141 \|$ \\
\hline Myocardial infarction: $\mathrm{n}(\%)$ & $2(0.8 \%)$ & $2(0.8 \%)$ & $1.0 \|$ \\
\hline Sternal wound infection: $\mathrm{n}(\%)$ & $1(0.4 \%)$ & $1(0.4 \%)$ & $1.0 \|$ \\
\hline Sepsis: n $(\%)$ & $2(0.8 \%)$ & $4(1.5 \%)$ & $.686 \|$ \\
\hline Stroke: n $(\%)$ & $1(0.4 \%)$ & $6(2.3 \%)$ & $.123 \|$ \\
\hline Pulmonary complication: $\mathrm{n}(\%)$ & $24(9.1 \%)$ & $32(12.2 \%)$ & $.258 \ddagger$ \\
\hline Renal failure: $\mathrm{n}(\%)$ & $1(0.4 \%)$ & $6(2.3 \%)$ & $.061 \|$ \\
\hline Atrial fibrillation: $\mathrm{n}(\%)$ & $67(26.3 \%)$ & $71(27.0 \%)$ & $.844 \dagger$ \\
\hline IABP: n (\%) & $2(0.8 \%)$ & $6(2.3 \%)$ & $.285 \|$ \\
\hline Use of inotropes: $\mathrm{n}(\%)$ & $95(36.1 \%)$ & $123(46.8 \%)$ & $.013 \dagger \dagger$ \\
\hline
\end{tabular}

$P R D$, Preoperative renal dysfunction; $C P B$, cardiopulmonary bypass; $S D$, standard deviation; $I Q R$, interquartile range; $L I C U$, length of intensive care unit stay; $L C O S$, low cardiac output syndrome; IABP, intra-aortic balloon pump. *Two-sample $t$ test. $\dagger P<.05 . \ddagger \chi^{2}$ test. $\S$ Kruskal-Wallis equality-of-populations rank test. \|Fisher exact test.

large study did not analyze the differential effect of renal dysfunction in patients undergoing AVS versus MVS. Our results show a clear difference between AVS and MVS, with PRD predicting mortality only in the MVS group. Also, the magnitude of the effect in MVS in our study (odds ratio $=10.4$ ) is greater than Howell and colleagues ${ }^{26}$ observed even in their group with the most severe renal dysfunction undergoing isolated valve surgery (odds ratio $=6.97$ ).

Similarly, Diez and colleagues ${ }^{27}$ reported mild renal dysfunction, defined as an estimated GFR less than $60 / \mathrm{mL}$ per $1.73 \mathrm{~m}^{2}$, as a predictor of in-hospital mortality. Their sample included 994 patients with isolated or combined valve and CABG surgery. However, isolated aortic valve or mitral valve replacement represented only 307 and 115 patients, respectively. Estimated GFR predicted mortality and postoperative acute renal failure; however, the independent association based on valve site was not reported. Therefore, a direct comparison with our results is not possible.

Interestingly, our study failed to demonstrate a correlation of PRD and postoperative renal failure, defined as the need for renal replacement therapy. Likely, this is due to the fact that only 17 patients (AVS, $n=10$; MVS, 


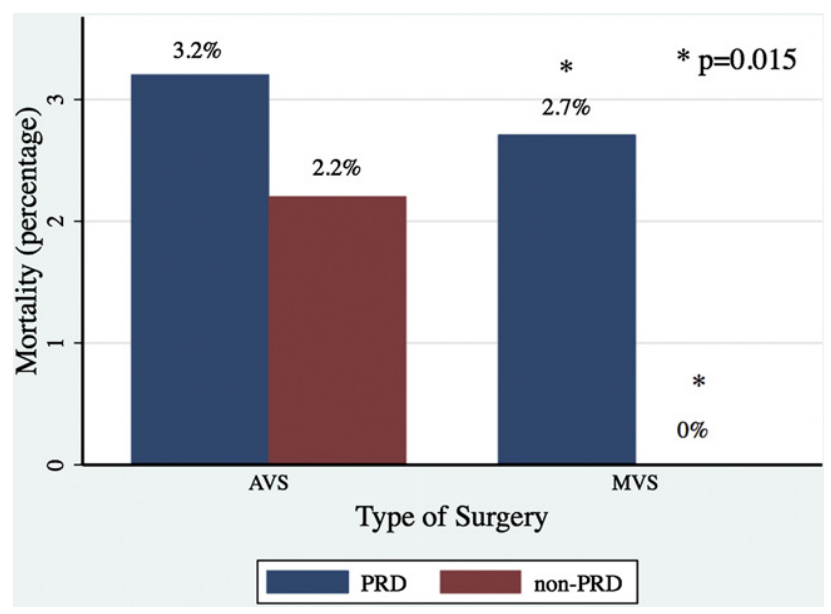

FIGURE 1. Operative mortality in the mitral valve surgery and aortic valve surgery propensity score matched samples. AVS, Aortic valve surgery; $M V S$, mitral valve surgery; $P R D$, perioperative renal dysfunction (non-dialysis dependent); non-PRD, no perioperative renal dysfunction.

$\mathrm{n}=7$ ) in the entire cohort required dialysis. The differential effect of PRD on AVS and MVS was a surprising finding and, to our knowledge, has not been previously described. We hypothesize that patients undergoing MVS are less tolerant of postoperative fluid retention owing to their volume overload physiology and thus suffer to a greater proportion from a similar degree of renal dysfunction. Alternatively, patients undergoing AVS were more likely to suffer from aortic stenosis and thus their renal dysfunction may comprise a more "prerenal" component than those patients undergoing MVS. However, our data do not support any association between type of valve disease, as a surrogate of intracardiac pressure or volume overload physiology, and outcomes in this study (data not provided). In summary, our results are in agreement with previous reports in this area but definitely expand and clarify the relationship between PRD and OM in isolated valve surgery. The novel aspects of our study include the use of propensity score matching to balance demographic differences and the consideration of the intrinsic differences between aortic and mitral valve disease.

There are several limitations to our study. First, despite the use of a standard propensity matched sampling technique, the distribution of BSA is unequal. However, the BSA distributions are unlikely to explain the results, particularly in MVS, where the concept of prosthesis-patient mismatch is less established. ${ }^{28,29}$ Second, more aggressive diuretic therapy may be necessary in advanced cases of valve disease, which can exacerbate PRD. Despite the use of propensity scores, we were unable to document actual diuretic therapy in each patient. Third, our estimation of GFR was performed with the Cockcroft-Gault formula and not with more recent equations such as the Modification of Diet in Renal Disease, which is the basis for the current chronic kidney disease classification. However, all equations for estimation of GFR are by definition only an approximation of the real physiologic GFR. Fourth, we did not explore as covariates the use of aprotinin, colloids, or blood products. Fifth, we did not differentiate between acute and chronic valvular disease, nor did we assess the chronicity of PRD. However, surgery was performed in an urgent or emergency fashion in less than $7 \%$ of these cases. Therefore, the vast majority of these patients had chronic valvular disease. Sixth, the PRD MVS group has a relatively higher proportion of mitral valve replacement than did the nonPRD MVS group, which is not statistically significant. Considering that we did not performed statistical adjustment for multiple analysis, we do not believe this is a statistical type I error and consequently not a real bias. Seventh, the time between preoperative angiography and the determination of estimated GFR was also variable, but is likely equally distributed among all groups. Finally, the number of events for our main outcome, OM, is small and therefore the generalizability of our conclusions may be limited.

\section{CONCLUSIONS}

In conclusion, our results demonstrate that PRD is associated with OM in MVS but not in AVS. In addition, PRD is associated with clinically significant morbidity in patients undergoing MVS, with a smaller impact in AVS.

This is the first study to distinguish the effects of PRD between AVS and MVS. We concede that this is an observational study, limited to perioperative outcomes. The potential differential effects of PRD on long-term clinical outcomes should be investigated in a similar manner. We hypothesize that renal function may improve after AVS for aortic stenosis, but may worsen after MVS for valvular insufficiency.

\section{References}

1. Coresh J, Astor BC, Greene T, Eknoyan G, Levey AS. Prevalence of chronic kidney disease and decreased kidney function in the adult US population: Third National Health and Nutrition Examination Survey. Am J Kidney Dis. 2003;41: $1-12$.

2. Levey AS, Atkins R, Coresh J, Cohen EP, Collins AJ, Eckardt KU, et al. Chronic kidney disease as a global public health problem: approaches and initiativesa position statement from Kidney Disease Improving Global Outcomes. Kidney Int. 2007;72:247-59.

3. Levin A, Hemmelgarn B, Culleton B, Tobe S, McFarlane P, Ruzicka M, et al. Guidelines for the management of chronic kidney disease. CMAJ. 2008;179: 1154-62.

4. Sarnak MJ, Levey AS, Schoolwerth AC, Coresh J, Culleton B, Hamm LL, et al Kidney disease as a risk factor for development of cardiovascular disease: a statement from the American Heart Association Councils on Kidney in Cardiovascular Disease, High Blood Pressure Research, Clinical Cardiology, and Epidemiology and Prevention. Circulation. 2003;108:2154-69.

5. Stigant C, Stevens L, Levin A. Nephrology: 4. Strategies for the care of adults with chronic kidney disease. CMAJ. 2003;168:1553-60.

6. Karkouti K, Wijeysundera DN, Yau TM, Callum JL, Cheng DC, Crowther M, et al. Acute kidney injury after cardiac surgery: focus on modifiable risk factors Circulation. 2009;119:495-502. 
7. Candela-Toha A, Elias-Martin E, Abraira V, Tenorio MT, Parise D, de Pablo A, et al. Predicting acute renal failure after cardiac surgery: external validation of two new clinical scores. Clin J Am Soc Nephrol. 2008;3:1260-5.

8. Heise D, Sundermann D, Braeuer A, Quintel M. Validation of a clinical score to determine the risk of acute renal failure after cardiac surgery. Eur J Cardiothorac Surg. 2010;37:710-6.

9. Thakar CV, Worley S, Arrigain S, Yared JP, Paganini EP. Influence of renal dysfunction on mortality after cardiac surgery: modifying effect of preoperative renal function. Kidney Int. 2005;67:1112-9.

10. Wijeysundera DN, Karkouti K, Dupuis JY, Rao V, Chan CT, Granton JT, et al. Derivation and validation of a simplified predictive index for renal replacement therapy after cardiac surgery. JAMA. 2007;297:1801-9.

11. Chukwuemeka A, Weisel A, Maganti M, Nette AF, Wijeysundera DN, Beattie WS, et al. Renal dysfunction in high-risk patients after on-pump and off-pump coronary artery bypass surgery: a propensity score analysis. Ann Thorac Surg. 2005;80:2148-53.

12. Cooper WA, O'Brien SM, Thourani VH, Guyton RA, Bridges CR, Szczech LA, et al. Impact of renal dysfunction on outcomes of coronary artery bypass surgery: results from the Society of Thoracic Surgeons National Adult Cardiac Database. Circulation. 2006;113:1063-70.

13. Rao V, Weisel RD, Buth KJ, Cohen G, Borger MA, Shiono N, et al. Coronary artery bypass grafting in patients with non-dialysis-dependent renal insufficiency. Circulation. 1997;96(9 Suppl):II-38-43; discussion II-44-5.

14. Zakeri R, Freemantle N, Barnett V, Lipkin GW, Bonser RS, Graham TR, et al. Relation between mild renal dysfunction and outcomes after coronary artery bypass grafting. Circulation. 2005;112(9 Suppl):I270-5.

15. van Straten AH, Soliman Hamad MA, van Zundert AA, Martens EJ, Schonberger JP, de Wolf AM. Preoperative renal function as a predictor of survival after coronary artery bypass grafting: comparison with a matched general population. J Thorac Cardiovasc Surg. 2009;138:971-6.

16. Levey AS, Bosch JP, Lewis JB, Greene T, Rogers N, Roth D. A more accurate method to estimate glomerular filtration rate from serum creatinine: a new prediction equation. Modification of Diet in Renal Disease Study Group. Ann Intern Med. 1999;130:461-70.
17. Rosenbaum PR, Rubin DB. The central role of the propensity score in observational studies for causal effects. Biometrika. 1983;70:41-55.

18. Rosenbaum PR. Design of observational studies. New York: Springer; 2009.

19. Guo S, Fraset MW. Propensity score analysis: statistical methods and applications. Thousand Oaks (CA): SAGE Publications; 2010.

20. Faries L, Haro O. Analysis of observational health care data using SAS. Cary (NC): SAS Publishing; 2010.

21. Parsons L. Reducing bias in a propensity score matched-pair sample using greedy matching techniques [SAS SUGI paper 214-26]. Proceeding of the 26th annual SAS User's Group International Conference, Cary (NC): SAS Institute. Retrieved 13 Sept 2010, from www2.sas.com/proceedings/sugi26/p214-26.pdf

22. Anderson RJ, O’Brien M, MaWhinney S, VillaNueva CB, Moritz TE, Sethi GK, et al. Mild renal failure is associated with adverse outcome after cardiac valve surgery. Am J Kidney Dis. 2000;35:1127-34.

23. Abramov D, Tamariz M, Fremes S, Tobe S, Christakis G, Guru V, et al. Impact of preoperative renal dysfunction on cardiac surgery results. Asian Cardiovasc Thorac Ann. 2003;11:42-7.

24. Filsoufi F, Rahmanian PB, Castillo JG, Silvay G, Carpentier A, Adams DH. Predictors and early and late outcomes of dialysis-dependent patients in contemporary cardiac surgery. J Cardiothorac Vasc Anesth. 2008;22:522-9.

25. Ibáñez J, Riera M, Saez de Ibarra JI, Carrillo A, Fernández R, Herrero J, et al. Effect of preoperative mild renal dysfunction on mortality and morbidity following valve cardiac surgery. Interact Cardiovasc Thorac Surg. 2007;6:748-52.

26. Howell NJ, Keogh BE, Bonser RS, Graham TR, Mascaro J, Rooney SJ, et al. Mild renal dysfunction predicts in-hospital mortality and post-discharge survival following cardiac surgery. Eur J Cardiothorac Surg. 2008;34:390-5; discussion 95.

27. Diez C, Mohr P, Kuss O, Osten B, Silber RE, Hofmann HS. Impact of preoperative renal dysfunction on in-hospital mortality after solitary valve and combined valve and coronary procedures. Ann Thorac Surg. 2009;87:731-6.

28. Brown ML, Schaff HV, Li Z, Suri RM, Daly RC, Orszulak TA. Results of mitral valve annuloplasty with a standard-sized posterior band: is measuring important? J Thorac Cardiovasc Surg. 2009;138:886-91.

29. Totaro P, Argano V. Patient-prosthesis mismatch after mitral valve replacement: myth or reality? J Thorac Cardiovasc Surg. 2007;134:697-701.

\section{APPENDIX 1. Propensity Score Methodology}

Propensity scores were constructed using the SAS PROC LOGISTIC for the multivariate logistic regression. Balancing properties of both propensity score models were optimal. Propensity score 1:1 matched samples were created independently; one for AVS and one for MVS using the SAS GREEDY $5 \rightarrow 1$ Digit Match Macro developed by Lori Parsons. ${ }^{17-21}$

\section{Variables Included in the AVS Propensity Score:}

1. Age

2. Left ventricular grade

3. Timing of the operation

4. New York Heart Association class

5. Diabetes mellitus

6. Hypertension

7. Hyperlipidemia

8. Preoperative myocardial infarction

9. Preoperative stroke

10. Peripheral vascular disease

11. Shock

12. Sex
13. Endocarditis

14. Any redo

15. Angina

16. Congestive heart failure

\section{Variables Included in the MVS Propensity Score:}

1. Age

2. Left ventricular grade

3. Timing of the operation

4. New York Heart Association class

5. Diabetes mellitus

6. Hypertension

7. Hyperlipidemia

8. Preoperative myocardial infarction

9. Preoperative stroke

10. Peripheral vascular disease

11. Shock

12. Sex

13. Endocarditis

14. Any redo

15. Angina

16. Congestive heart failure 


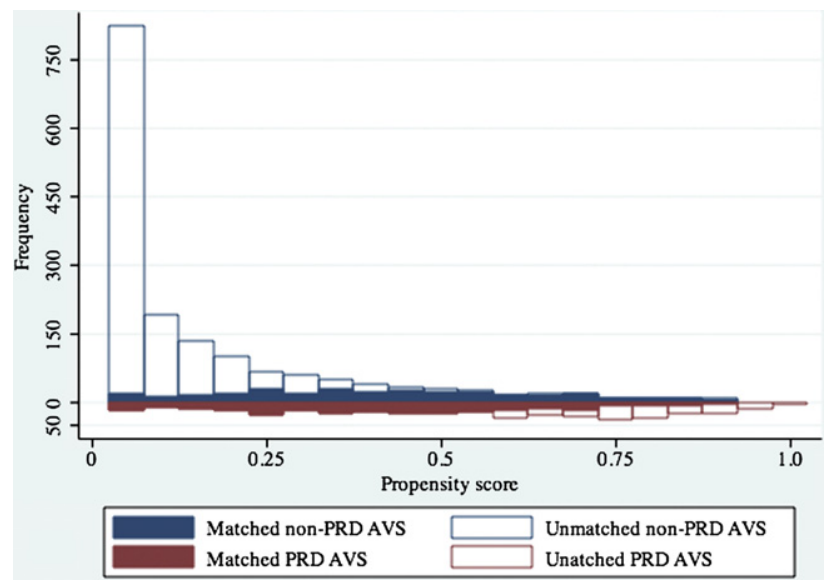

APPENDIX 2. Mirrored histogram of distribution of the propensity scores for unmatched and matched aortic valve surgery samples. AVS, Aortic valve surgery; $P R D$, perioperative renal dysfunction (non-dialysis dependent); non-PRD, no perioperative renal dysfunction.

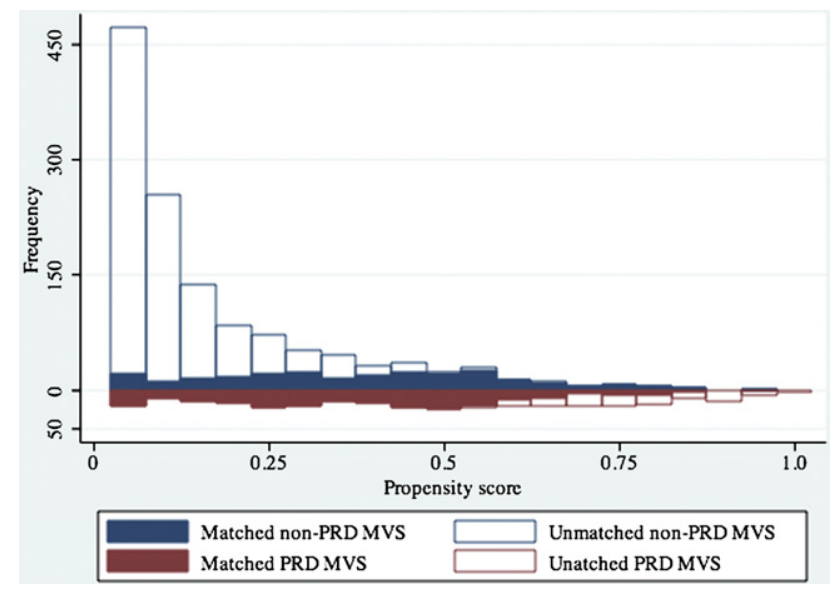

APPENDIX 3. Mirrored histogram of distribution of the propensity scores for unmatched and matched mitral valve surgery samples. MVS, mitral valve surgery; $P R D$, perioperative renal dysfunction (non-dialysis dependent); non- $P R D$, no perioperative renal dysfunction.

\section{APPENDIX 4. Type of valvular lesion}

\begin{tabular}{lrrrrr}
\hline Variable & Non-PRD & & PRD & & $P$ value \\
\hline Aortic valve surgery & & & & & \\
$\quad$ Valve disease & & $\mathrm{n}$ & & $\mathrm{n}$ & $.515^{*}$ \\
$\quad$ Stenosis & $61.7 \%$ & 192 & $59.9 \%$ & 185 & \\
$\quad$ Regurgitation & $19.9 \%$ & 62 & $24.3 \%$ & 75 & \\
$\quad$ Mixed & $17.0 \%$ & 53 & $15.2 \%$ & 47 & \\
$\quad$ None & $1.3 \%$ & 4 & $0.7 \%$ & 2 & \\
Mitral valve surgery & & & & & \\
$\quad$ Valve disease & & $\mathrm{n}$ & & $\mathrm{n}$ & $.873^{*}$ \\
$\quad$ Stenosis & $10.5 \%$ & 27 & $9.7 \%$ & 25 & \\
$\quad$ Regurgitation & $77.0 \%$ & 198 & $75.7 \%$ & 196 & \\
$\quad$ Mixed & $12.1 \%$ & 31 & $14.3 \%$ & 37 & \\
$\quad$ None & $0.4 \%$ & 1 & $0.4 \%$ & 1 & \\
\hline
\end{tabular}

PRD, Preoperative renal dysfunction. *Fisher exact test.

APPENDIX 5. Clinical data in patients with perioperative death from the matched mitral valve surgery groups by patient

\begin{tabular}{lccccccccc}
\hline Patient & PRD status & Age (y) & Year & CHD & MVR & MAR & Redo & Time to death (mo) & Cause of death \\
\hline 1 & Yes & 23 & 1996 & No & Yes & Yes & No & 3 & Sepsis (IE) \\
2 & Yes & 65 & 1998 & No & Yes & No & Yes & 172 & MOF \\
3 & Yes & 65 & 1999 & No & Yes & No & Yes & 3 & MOF \\
4 & Yes & 47 & 2001 & No & Yes & No & No & 0 & OR death \\
5 & Yes & 73 & 2001 & No & Yes & Yes & Yes & 21 & CVA \\
6 & Yes & 71 & 2005 & No & Yes & Yes & No & 0 & OR death \\
7 & Yes & 34 & 2009 & Yes & No & No & No & 2 & Heart/renal failure \\
\hline
\end{tabular}

$P R D$, Preoperative renal dysfunction; $C H D$, congenital heart disease; $M V R$, mitral valve replacement; $M A R$, mitral annulus reconstruction; $I E$, infective endocarditis; $M O F$, multiorgan failure; $O R$, operating room; $C V A$, cerebrovascular accident. 